\title{
Rheological and Fatigue Characterisation of Bitumen Modified by Anti-ageing Compounds ${ }^{1}$
}

\author{
Eman L. Omairey ${ }^{1}$, Yuqing Zhang ${ }^{*}$, Fan $\mathrm{Gu}^{1}$, Tao $\mathrm{Ma}^{2}$, Pengsen $\mathrm{Hu}^{3}$, and Rong Luo ${ }^{4}$ \\ ${ }^{1}$ Aston Institute of Materials Research, Aston University \\ Aston Triangle, Birmingham, B4 7ET (United Kingdom) \\ *Corresponding Author (y.zhang10@aston.ac.uk) \\ ${ }^{2}$ School of Transportation, Southeast University \\ 2 Southeast University Road, Jiangning District, Nanjing, 211189 (China) \\ ${ }^{3}$ Department of Civil and Environmental Engineering, The Pennsylvania State University \\ University Park, State College, PA 16802 (United States) \\ ${ }^{4}$ School of Transportation, Wuhan University of Technology \\ 1178 Heping Avenue, Wuhan, Hubei Province 430063 (China)
}

\begin{abstract}
When exposed to the ambient environment for an extended period, bitumen ages and causes the failure of asphalt pavement, the addition of anti-ageing compounds (AACs) to bitumen binders can prolong the service life of the pavement. This study investigates the effects of anti-ageing compounds on the fatigue performance of bitumen when subjected to different ageing conditions. The AAC-modified bitumen binders were tested by dynamic shear rheometer (DSR) and Fourier transform infrared spectroscopy test (FTIR) at different ageing conditions including unaged, short-term ageing by thin film oven test (TFOT) and long-term ageing by pressure ageing vessel (PAV). The fatigue performance of the AAC-modified bitumen was characterised by the dissipated energy ratio (DER), SHRP fatigue parameter and the DSR-cracking (DSR-C) approach developed by the authors. Linear amplitude sweep (LAS) tests were firstly run at $20{ }^{\circ} \mathrm{C}, 10 \mathrm{~Hz}$ and $0.1-15 \%$ controlled shear strain conditions, to obtain the phase angles and shear moduli at the undamaged conditions. Time sweep (TS) tests were then conducted at $5 \%$ shear strain, also at $20{ }^{\circ} \mathrm{C}$ and $10 \mathrm{~Hz}$, and up to 24000 loading cycles to obtain phase angles, shear moduli and DER at damaged conditions. The crack lengths in the TS tests were calculated by DSR-C model and then validated by the image analysis method. The results suggest that, compared to the DER or SHRP fatigue parameter, DSR-C predicted crack lengths show a more consistent and reliable agreement with laboratory measurements. DSR-C test can differentiate fatigue cracking performance among binders modified with AACs, and the normalised carbonyl index may be a reliable parameter to reflect the impact of ageing products on the fatigue resistance of AAC-modified binders. Bitumen samples modified with 12\% (1 furfural: 5 Irganox 1076), 15\% Irganox 1076 and 3.5\% (3 DLTDP: 4 furfural) demonstrated the best anti-ageing behaviour by retarding carbonyl content growth and decreasing the fatigue damage among selected AACs without sacrificing the stiffness of binder. However, rutting susceptibility at earlier stages of service life needs further investigations.
\end{abstract}

Keywords: Bitumen, Anti-Ageing Compounds, Fatigue Cracking, Dynamic Shear Rheometer, Carbonyl Index.

\section{Introduction}

\subsection{Oxidative Ageing}

Bitumen is a hydrocarbon product produced by removing light fractions (such as liquid petroleum gas, petrol and diesel) from crude oil during the refining process [1,2]. Bitumen is largely prone to oxidative ageing, which causes hardening of the material and increases the likelihood of fracture behaviour of a pavement due to the decreased resistance to fatigue cracking [1]. The fatigue cracking is a result of repeated traffic loads as well as pavement materials degradation under rigorous environmental conditions like exposure to heat, solar radiation and oxygen from the air. The in-service asphalt pavements are more susceptible to fatigue cracking at later stages of their life as asphalt mixtures become brittle due to ageing. The fatigue resistance of bitumen binders was found to fundamentally determine and directly correlate to the fatigue resistance of the asphalt mixtures [3,4]. Therefore, one of the solutions to prolong the service life of the asphalt pavements is by modifying the bitumen with anti-ageing compounds (AACs).

${ }^{1}$ This is an accepted manuscript for a paper published by the Journal of Construction and Building Materials. The full text of the paper is available at: https://doi.org/10.1016/j.conbuildmat.2020.120307 
AACs are believed to reduce the oxidative ageing, which is one of the major contributors to pavement ageing [5]. Researchers found that these additives can reduce the growth of oxidation products such as carbonyl and sulfoxides $[6,7]$. The growth of oxidation products associates with the increase in molecular size of asphaltenes, resins and reduction of free volume space for saturates, causing less molecular diffusion and decreases the self-healing capability of bitumen and leads to bitumen hardening [8]. Therefore, inducing AACs reduces bitumen hardening, enhances the fatigue performance of asphalt pavements and prolongs their service life. However, a direct linkage between the anti-ageing efficiency of AACs and the mechanical performance of asphalt binders, particularly reduced fatigue crack length, was not investigated in detail.

\subsection{Fatigue Characterisation}

Existing studies characterised the fatigue behaviour of asphalt binders by imploying the dynamic shear rheometer (DSR) test, and the criterion of fatigue failure of bitumen binders was a subject of on-going research [3, 4, 9-12]. Many studies stated the Superpave asphalt binder specification criterion for fatigue characterisation to be inaccurate practice, particularly for polymer-modified bitumen. Mainly because the Superpave fatigue parameter $\left(\left|G^{*}\right| \cdot \sin \delta\right)$ relays on the linear viscoelastic properties at undamaged conditions (relatively small strain levels). Still, in reality, the fatigue failure occurs at high strain levels where the bitumen is in damaged conditions. Therefore, the use of undamaged viscoelastic properties alone yields inaccurate fatigue characterisation, and this seems to be more pronounced in modified bitumen $[9,12,13]$. Thus, a different fatigue evaluation term called the dissipated energy ratio (DER) was employed to characterise the fatigue behaviour of asphalt binders. DER gave a better representation of the fatigue properties of a various range of binders [10-12]. DER is represented by Eqs. (1), (2) and (3) [10].

$$
\begin{array}{r}
W_{i}=\pi \sigma_{i} \gamma_{i} \sin \left(\delta_{i}\right) \\
W_{\sum n}=\sum_{i=1}^{n} W_{i} \\
D E R=\frac{W_{\sum n}}{W_{n}}
\end{array}
$$

where

$W_{i}=$ dissipated energy density at load cycle $i$

$\sigma_{i}=$ stress amplitude at load cycle $i$

$\gamma i=$ strain amplitude at load cycle $i$

$\delta i=$ phase angle at load cycle $i$

$\sum W_{i}=$ cumulative dissipated energy $\left(W_{n}\right)$ up to cycle $n$

A new fatigue measure for asphalt binders was proposed recently by the authors using a DSR-based crack (DSR-C) growth model derived from dissipated strain energy equilibrium principle and damage mechanics [14]. The study employed the DSR test to determine the shear moduli and phase angles at both undamaged and damaged conditions. Two DSR testing schemes were adopted: (1) The linear amplitude sweep (LAS) to obtain the undamaged material properties; (2) The time sweep (TS) tests to obtain the fatigue properties at the damaged condition. Results were validated at different temperatures, frequencies and strain levels [14]. The fatigue damage was quantified directly by a predicted crack length $\left(c_{p}\right)$, illustrated in Eq. (4).

$$
c_{p}=\left[1-\left(\frac{\left|G_{N}^{*}\right| / \sin \left(\delta_{N}\right)}{\left|G_{o}^{*}\right| / \sin \left(\delta_{o}\right)}\right)^{\frac{1}{4}}\right] r_{o}
$$

where

$r_{o}=$ the original radius of the sample

$\left|G_{N}^{*}\right|,\left|G^{*}{ }_{o}\right|=$ the shear moduli for the damaged and undamaged samples, respectively

$\delta_{N}, \delta_{o}=$ the phase angles of the damaged and undamaged samples, respectively.

$c_{p}=$ the predicted crack length at the $\mathrm{N}^{\text {th }}$ loading cycle of time sweep fatigue test.

The crack length predicted by DSR-C model (Eq.4) was effectively validated for virgin and polymer-modified bitumen at different loading and temperature conditions. A digital visualisation approach similar to that employed by Hintz and Bahia (2013) and Shan et al. (2017) was adopted for DSR-C model validation [15, 16]. The fatigue evaluation approaches mentioned earlier are used in the present study to investigate the fatigue performance of bitumen modified with different AACs.

\subsection{Oxidative Chemical Changes and Fatigue Behaviour}

Some studies focused on the links between the ageing-induced chemical changes and the fatigue and healing behaviour of bitumen $[17,18]$. The SARA (saturates, aromatics, resins and asphaltenes) fractionation technique was utilised for this purpose. It was observed that a higher ratio of flocculated fractions (asphaltenes and saturates) to 
dispersed constituents (aromatics and resins) in bitumen led to higher $\left|G^{*}\right| \cdot \sin \delta$ value. This observation means the higher the flocculated content, the stiffer will be the bitumen [19-22]. Therefore the bitumen will be more prone to fatigue cracking. Others investigated the effect of molecular size of bitumen components on the fatigue properties of asphalt binders by using Size Exclusion Chromatography test [20, 22, 23]. Findings explained that existence of small molecules within the binder is favourable for improving the fatigue resistance performance and bigger size molecules generate poor fatigue resistance. However, the use of SARA fractionation techniques and molecular size analysis brings limitation concerns due to the continuous introduction of various new types of modifiers and chemical additives to bitumen [20,21]. These standard practices are designed to analyse the bitumen without any modifiers. When used for modified binders, these tests can only characterise the chemical composition of their base binders rather than the combination of bitumen with chemical additives [20]. Thus, a direct correlation between the oxidative ageing products and fatigue performance for aged asphalt binders (including those modified with AACs) is needed.

There are a few attempts to correlate the fatigue behaviour of bitumen to its molecular structure by using FTIR test results [22, 23]. These attempts utilised FTIR absorption peaks 1600, 1460, and $1376 \mathrm{~cm}^{-1}$ to characterise the fatigue damage behaviour of asphalt binders, where those peaks represent the benzene ring, methylene $\mathrm{CH}_{2}$ and methyl $\mathrm{CH}_{3}$, respectively. These functional groups are employed to evaluate the chemical structures of bitumen, where the higher the ratio of area under peak $1460 \mathrm{~cm}^{-1}$ to that for peak $1376 \mathrm{~cm}^{-1}$, the lower the branched-chain molecules. In contrast, the higher the area under peak $1600 \mathrm{~cm}^{-1}$, the higher the molecular weight of bitumen. However, peaks 1600, 1460 and $1376 \mathrm{~cm}^{-1}$ remain unchanged during ageing [8]. Therefore, this FTIR analysis approach cannot evaluate the ageing effects on the fatigue behaviour of bitumen binders. It is believed that the pavements are more susceptible to fatigue cracking at later stages of their service lives when the asphalt is severely aged [24, 25], and ageing induced growth of oxidation products affects the binder-aggregate molecular adhesion properties [26, 27]. Therefore, further studies are needed to show the links between the chemical functional groups and the fatigue performance of long-term aged (LT-aged) modified-asphalt binders.

\subsection{Objectives of the Study}

The objective of this study is to evaluate the fatigue performance of LT-aged bitumen modified with six different types of AACs. An effective AAC will be nominated for the asphalt binder to generate AAC-modified bitumen with good resistance to both oxidative ageing and fatigue cracking. Moreover, the study attempts to link the chemical structure of an aged bitumen to its fatigue performance. DSR-C fatigue test and FTIR test are utilised to determine the fatigue performance and oxidation products of AAC-modified binders.

Although the study emphases on the fatigue behaviour of AAC-modified asphalt binder at intermediate temperatures, it also examines the high-temperature performance and the thermal stability of nominated AAC-modified bitumen to cover more aspects concerning effects of AACs on bitumen. Therefore, the differential scanning calorimetry (DSC) test was employed to examine the oxidation onset temperature (OOT) of the AAC-modified bitumen, and the multiple stress creep and recovery (MSCR) test was utilised to measure the rutting susceptibility of AACmodified bitumen at high temperatures.

The types and concentrations of AACs in the binder were based on the recent findings reported in [8] and [28], the additives were selected based on an initial screening protocol using thin-film aged bitumen samples and FTIR tests. Following this initial screening, a detailed performance evaluation at the long-term ageing conditions is performed to consider these AAC to be anti-ageing effective, which is addressed in this paper.

\section{Materials and Methods}

\subsection{Preparation of AAC-Modified Bitumen Samples}

A control bitumen with a standard penetration grade of 60 , was used as a base (control) sample. Table 1 lists the standard engineering specifications of the binder. One type of bitumen was examined in this study for all tests to reduce the binder-source effects [7, 29-32], and the initial screening tests for AACs (covered in an earlier paper by the authors) were conducted on a different source of bitumen. Nonetheless, AACs are known to have different levels of effectiveness on different binder types, and any AAC should be tested on the binder type before use.

Table 1 Standard physical properties of control bitumen

\begin{tabular}{ll}
\hline Test index & Value \\
\hline Penetration $\left(15^{\circ} \mathrm{C}\right) \mathbf{0 . 1} \mathbf{~ m m}$ & 24.6 \\
\hline Penetration $\left(25^{\circ} \mathbf{C}\right) \mathbf{0 . 1} \mathbf{~ m m}$ & 60.7 \\
\hline Penetration $\left(30^{\circ} \mathbf{C}\right) \mathbf{0 . 1} \mathbf{~ m m}$ & 106.27 \\
\hline
\end{tabular}




\begin{tabular}{|c|c|}
\hline Softening point ${ }^{\circ} \mathrm{C}$ & 48.6 \\
\hline Ductility $\left(5^{\circ} \mathrm{C}\right) \mathrm{cm}$ & 5.7 \\
\hline Ductility $\left(15^{\circ} \mathrm{C}\right) \mathrm{cm}$ & $>150$ \\
\hline Viscosity $\left(135^{\circ} \mathrm{C}\right)$ Pa.s & 0.4363 \\
\hline
\end{tabular}

The bitumen was mixed with AACs to formulate AAC-modified bitumen samples. The AACs concentration was based on two aspects: (1) Availability of the materials to be used in large quantities; (2) Previous literature review concerning the expected reaction of each additive $[1,7,28]$. The AACs were mixed as percentages of the mass of binder, as specified in Table 2.

The bitumen and AACs were blended using a high-speed shear mixer (FLUKO FM300) to ensure full dispersion of the additives. The mixing process was done at a rotation speed of $4000 \mathrm{rpm}$ for 90 minutes under controlledtemperature conditions. The temperature was kept in a range of (120-150) ${ }^{\circ} \mathrm{C}$ during the mixing process to prevent excessive ageing. The control bitumen sample (without additives) was subjected to the same mixing process to ensure that all samples experience identical mixing and ageing conditions. Following mixing, part of the binderAAC mixture was stored in air-tight containers to be tested under the unaged conditions. The remaining specimens were cast into flat containers to be subjected to short-term ageing (ST) and long-term ageing (LT) conditions using Thin Film Oven test (TFOT, ASTM standard D1754-97) and Pressurized Ageing Vessel test (PAV, ASTM standard D6521-18), respectively [33, 34].

Table 2 Anti-ageing compounds and concentrations in modified bitumen

\begin{tabular}{lll}
\hline $\begin{array}{l}\text { Specimen } \\
\text { ID }\end{array}$ & Additive & $\begin{array}{l}\text { Additive concentration } \\
\text { (\% by mass of bitumen binder) }\end{array}$ \\
\hline $\mathbf{1}$ & Control sample (no additives) & N/A \\
\hline $\mathbf{2}$ & Trimethylolpropane TMP & 10 \\
\hline $\mathbf{3}$ & Furfural & 2 \\
\hline $\mathbf{4}$ & Sodium montmorillonite & 15 \\
\hline $\mathbf{5}$ & (1:5) Furfural: Irganox 1076 & 12 \\
\hline $\mathbf{6}$ & Irganox 1076 & 15 \\
\hline $\mathbf{7}$ & (3:4) DLTDP ((Dilauryl) Thiodipropionate): furfural & 3.5 \\
\hline
\end{tabular}

\subsection{Anti-Ageing Materials Selection Criteria}

The AACs selection criteria were based on a preliminary AAC screening method, which was reported in a separate paper [7]. The initial screening tests comprised of mixing the AACs with bitumen at room temperature with the aid of a solvent at different concentrations of AACs, then placing a thin film of the AAC-modified bitumen on FTIR screening plate and ageing it at $100{ }^{\circ} \mathrm{C}$ in the oven for extended periods up to two weeks of ageing. FTIR results were analysed to quantify the oxidative chemical products (Carbonyl $\mathrm{C}=\mathrm{O}$ and Sulfoxide $\mathrm{S}=\mathrm{O}$ functional groups). The AACs were selected as those causing less growth rate of oxidation products in the modified bitumen than that in the control bitumen, and the oxidation activation energy of bitumen was selected as the parameter for comparing the effectiveness of AACs. A list of the AACs selected based on the preliminary AAC screening, and their concentrations are summarised in Table 2. The specimens identification numbers, which are listed in Table 2 will be used to refer to the samples in this study. It is noted that the elected AACs from initial screening protocol [7] need further investigation to ensure AAC-modified bitumen has a satisfactory engineering performance. This research will cover this part of work by using the standard ageing protocols and rheological and thermal tests to investigate the effectiveness of these elected additives.

The additives, furfural, (Dilauryl) thiodipropionate (DLTDP), Irganox 1076, sodium montmorillonite (NaMMT) and trimethylolpropane (TMP) were mixed with the bitumen by mass percentages of bitumen. These materials are believed to increase the bitumen resistance to thermal instability and permanent deformations [28, 35-37]. The chemical structures and physical characteristics of selected anti-ageing compounds are listed in Table 3.

Table 3 Chemical and physical characteristics of nominated anti-ageing compounds

\begin{tabular}{|c|c|c|c|c|}
\hline $\begin{array}{l}\text { Common } \\
\text { name }\end{array}$ & $\begin{array}{l}\text { Identity/ } \\
\text { classifica- } \\
\text { tion }\end{array}$ & State & $\begin{array}{l}\text { (Melting } \\
\text { point) Boil- } \\
\text { ing point } \\
\left({ }^{\circ} \mathrm{C}\right)\end{array}$ & $\begin{array}{l}\text { Solubility in wa- } \\
\text { ter }(\% \mathrm{w} / \mathrm{w})\end{array}$ \\
\hline
\end{tabular}

Chemical structure 


\begin{tabular}{|c|c|c|c|c|c|}
\hline Furfural & $\begin{array}{l}\text { organic al- } \\
\text { dehyde }\end{array}$ & liquid & $(-38) 162$ & 7.4 & 2-Furaldehyde \\
\hline \multirow[t]{2}{*}{ DLTDP } & $\begin{array}{l}\text { organic thi- } \\
\text { oester }\end{array}$ & solid & $(39-42)$ & $<0.01$ & ${ }^{0} \nsucc$ \\
\hline & & & & & didodecyl 3, 3'-thiopropionate \\
\hline \multirow[t]{2}{*}{$\begin{array}{l}\text { Irganox } \\
1076\end{array}$} & $\begin{array}{l}\text { Hindered } \\
\text { phenol or- } \\
\text { ganic ester/ } \\
\text { antioxidant }\end{array}$ & solid & $(50-55)$ & $<0.01$ & 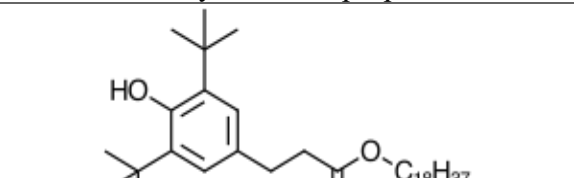 \\
\hline & & & & & $\begin{array}{l}\text { Octadecyl-3-(3,5-di-tert.butyl-4-hydroxy- } \\
\text { phenyl)-propionate }\end{array}$ \\
\hline \multirow[t]{2}{*}{$\begin{array}{l}\text { Trime- } \\
\text { thylolpro- } \\
\text { pane } \\
\text { (TMP) }\end{array}$} & $\begin{array}{l}\text { organic tri- } \\
\text { hydroxy al- } \\
\text { cohlol }\end{array}$ & solid & (58) 285 & $>10$ & $\mathrm{OH}$ \\
\hline & & & & & 1,3-Propanediol, 2-ethyl-2-(hydroxymethyl)- \\
\hline NaMMT & $\begin{array}{l}\text { Inorganic } \\
\text { silicate/clay }\end{array}$ & solid & none & insoluble & $(\mathrm{Na}, \mathrm{Ca}) 0,3(\mathrm{Al}, \mathrm{Mg}) 2 \mathrm{Si} 4 \mathrm{O} 10(\mathrm{OH}) 2 \bullet \mathrm{n}(\mathrm{H} 2 \mathrm{O})$ \\
\hline
\end{tabular}

\subsection{Dynamic Shear Rheometer (DSR) Tests}

The dynamic shear rheometer (DSR) is used to determine the rheological properties of asphalt binder using Malvern Instruments Kinexus device. Bitumen samples are heated to $130{ }^{\circ} \mathrm{C}$ and poured into $8 \mathrm{~mm}$ diameter moulds $(2 \mathrm{~mm}$ vertical gap) or $25 \mathrm{~mm}$ diameter moulds (1 mm vertical gap). The samples are prepared using silicone moulds. The hot bitumen from a heated container is poured into the mould to form a convex surface, and then the filled mould is cooled to room temperature without chilling. Then, the bitumen is loosened from the mould by flexing the rubber mould and is adhered to the preheated lower test plate by gently pressing the convex (top) surface of the pellet. After that, the upper test plate is moved until the gap between the plates equals the testing gap ( $2 \mathrm{~mm})$ plus the gap closure required to create a slight bulge at the outside face of the test specimen. The excess bitumen is trimmed by moving a heated trimming tool around the edges of the plates so that the bitumen is flush with the outer diameter of the plates. When the trimming is complete, the gap is decreased to the testing value $(2 \mathrm{~mm})$. Finally, the bitumen is heated to the testing temperature and then remained for 5 min before loading [14].

A series of DSR tests were conducted on unaged and LT-aged bitumen samples. Table 4 shows the testing schemes used in this study. The tests were run in duplicates. In case of inconsistent results for the repeats, tests were run in triplicates.

\subsubsection{Linear Amplitude Sweep Test}

Linear Amplitude Sweep (LAS) strain-controlled tests were conducted at an intermediate temperature of $20^{\circ} \mathrm{C}$ with $10 \mathrm{~Hz}$ frequency and $0.1 \%-15 \%$ strain values. The initial shear complex moduli $\left(G_{o}{ }^{*}\right)$, and phase angles $\left(\delta_{o}\right)$ were obtained at undamaged condition (where the shear moduli and phase angles remain unchanged with low strain levels). To investigate the high-temperature rheological changes in the bitumen due to AACs modification, LAS tests at high temperature $\left(64^{\circ} \mathrm{C}\right)$ are conducted solely for bitumen samples that demonstrate good fatigue cracking behaviour. The same testing parameters (i.e., load frequency and strain level) used in LAS tests at $20^{\circ} \mathrm{C}$ temperature, were employed for high-temperature tests.

\subsubsection{Time Sweep Fatigue Test}


The time sweep (TS) test is a strain-controlled fatigue test utilised to determine the complex shear moduli ( $\left.G^{*}\right)$ and phase angle $(\delta)$ at damaged condition (at 24,000 loading cycle), to evaluate fatigue performance of the modified binders. The tests are conducted at an intermediate temperature of $20{ }^{\circ} \mathrm{C}$ for $10 \mathrm{~Hz}$ frequency and $5 \%$ strain level, and up to 24,000 cycles (40 minutes). The plate used in this test is of $8 \mathrm{~mm}$ in diameter ( $2 \mathrm{~mm}$ vertical gap). The high strain (5\%) was selected as the strain level at which virgin bitumen and AAC-modified bitumen demonstrate significant damage, as indicated by the decreased modulus and increased phase angle from LAS test results.

\subsubsection{Image Analysis Method}

Image analysis method (IAM) is used to measure the fatigue cracking extent (crack length) at the end of the TS test. When the DSR completes 24,000 loading cycles, loading is stopped, and the temperature is set to cool down automatically to $3{ }^{\circ} \mathrm{C}$ to prevent the sample from melting and therefore preserve cracks morphology and geometry. The sample is then pulled apart axially by separating the top-loading plate from the bottom plate, and the cracking pattern on the bitumen sample is photographed. Figure 1 shows the cross-section of a damaged bitumen sample. The effective radius and original radius of samples are measured, where the effective radius $\left(r_{E}\right)$ is the radius of remained uncracked area at the centre of the sample. The effective radius is measured about the original radius $\left(r_{o}\right)$, which represents the radius of the sample at the undamaged condition ( $4 \mathrm{~mm}$ standard radius). Then the crack length is measured as $\left(c_{p}=r_{0}-r_{E}\right)$. Detailed steps to determine the crack length are reported in the literature [14]. The measured crack length is employed to validate predicted crack length by DSR-C model in Eq. (4).

The reason for selecting loading cycles $(n)$ to be 24,000 cycles is to verify the cracking damage magnitude obtained by the IAM. If the loading cycle at failure $\left(N_{f}\right.$ at which the DSR versus the loading cycle curve becomes nonlinear) $[10,11]$ was utilised to measure the crack length, it would not be possible to inspect the actual damage at that point. Therefore, the number of loading cycles at which the test ends were selected based on two aspects. The first aspect for selecting $(n=24,000)$ to be the loading cycle at which TS test stops, is that it was found previously that an intermediate crack length was formed at this stage of loading for two types of binders [14]. The second aspect is that measured cracks did not reach a complete failure $\left(c_{m}<4 \mathrm{~mm}\right)$. In other words, the sample is not completely separated into two parts at this stage of loading, although it shows measurable crack damage.

\subsubsection{Multiple Stress Creep and Recovery Test}

The multiple stress creep and recovery (MSCR) test is a standard test (ASTM standard D7405-15, AASHTO T 350), used to measure rutting susceptibility of bitumen at high temperatures [38]. This test is conducted solely on bitumen samples that demonstrates good fatigue resistance characteristics. The plate used in this test is the $25 \mathrm{~mm}$ diameter plate (1 mm vertical gap). The temperature for MSCR test is set to be Performance Grade (PG) hightemperature. The PG high-temperature is determined by the DSR device and high-temperature standard evaluation test (HT-PG) (using the standards AASHTO T-315) [39].

Table 4 DSR testing schemes

\begin{tabular}{lcccc}
\hline Test* & Temperature $\left({ }^{\circ} \mathrm{C}\right)$ & Frequency (Hz) & Strain level & $\begin{array}{l}\text { Number of cy- } \\
\text { cles }\end{array}$ \\
\hline LAS & 20 & 10 & $0.1 \%-15 \%$ & N/A \\
& 64 & & $5 \%$ & 24000 \\
\hline TS & 20 & \multicolumn{1}{c}{ Standard test (AASHTO T 315) } \\
\hline HT-PG & 64 & Standard test (AASHTO T 350) \\
\hline MSCR & *LS = linear amplitude sweep test; TS = time sweep test; HT-PG = high temperature Performance Grading \\
test; MSCR = multiple stress creep and recovery test
\end{tabular}




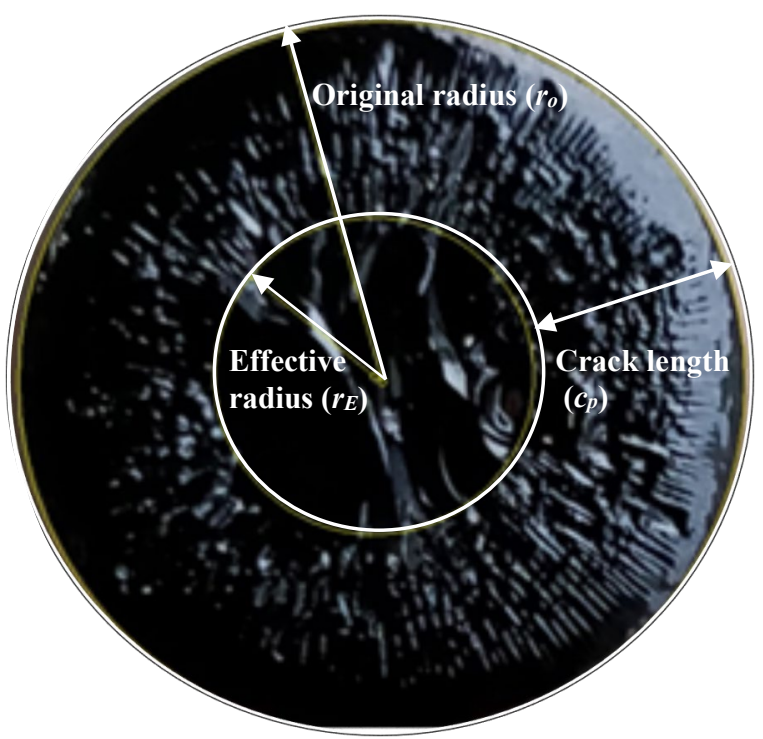

Fig. 1 Crack morphology of bitumen under shear fatigue loading. The effective radius calculated by the image analysis method.

\subsection{Fourier Transform Infrared Spectroscopy (FTIR) Test}

Fourier transform infrared spectroscopy (FTIR) tests were carried out for unaged and LT-aged bitumen samples using Thermo Scientific Nicolet iS10 spectrum. The device is set to scan in a range of (500-4000) $\mathrm{cm}^{-1}$, with a scanning frequency of 16 and $4 \mathrm{~cm}^{-1}$ resolution. $\mathrm{KBr}$ scanning plates with a $12 \mathrm{~mm}$ diameter are prepared by compressing $\mathrm{KBr}$ powder into thin discs (about $1 \mathrm{~mm}$ thickness). Then, a small amount of bitumen is placed close to the edge of newly prepared $\mathrm{KBr}$ plates and heated to $100 \pm 5^{\circ} \mathrm{C}$. A clean steel spatula also heated, then when the bitumen melts, it is levelled by the spatula into a thin layer, and cooled before scanning by FTIR, to observe the changes of chemical functional groups due to ageing in bitumen samples modified by AACs.

\subsection{Oxidation Onset Temperature (OOT) Test}

The differential scanning calorimetry (DSC) is reported to examine the thermal properties of asphalt binders [40]. This test is usually applied for polymeric materials to measure their thermal stability [41]. The oxidation onset temperature (OOT) is a testing scheme that examines the oxidation initiation temperature of materials in controlled temperature and pressure conditions. Therefore, it is used in this study to assess the thermal stability of AACsmodified bitumen in oxygen-exposed conditions and at a temperature range similar to that in the field. A higher OOT indicates better thermal stability at the oxygen-exposed condition for AAC-modified bitumen.

The OOT is performed using the DSC Netzsch high-temperature device. The test measures the temperature at which the oxidation process initiates by observing the change in heat flux for a sample placed inside oxygen gas chamber. The oxidation is an exothermic process which involves a decrease in heat flow (release of energy) when initiated (such as the burning process of hydrocarbon materials). In other words, the machine will release less heat flow to maintain the control temperature level during an exothermic process. The bitumen samples of $(0.05 \mathrm{~g}) \mathrm{mass}$ are placed in oxygen gas controlled-environmental cell and subjected to a $5{ }^{\circ} \mathrm{C} / \mathrm{min}$ temperature rate starting at 20 ${ }^{\circ} \mathrm{C}$ room temperature. The tests are stopped at a temperature of $150{ }^{\circ} \mathrm{C}$ to avoid reaching the flashpoint.

\section{Results}

\subsection{Linear Amplitude Sweep Test Results}

The linear amplitude sweep test (LAS) is conducted to obtain the initial phase angles $\delta_{\mathrm{o}}$ and shear moduli $G^{*}{ }_{o}$ at undamaged condition, at which the shear modulus and phase angle remain unchanged at relatively low strain levels (e.g., $<1 \%$ ), as shown in Figure 2. 


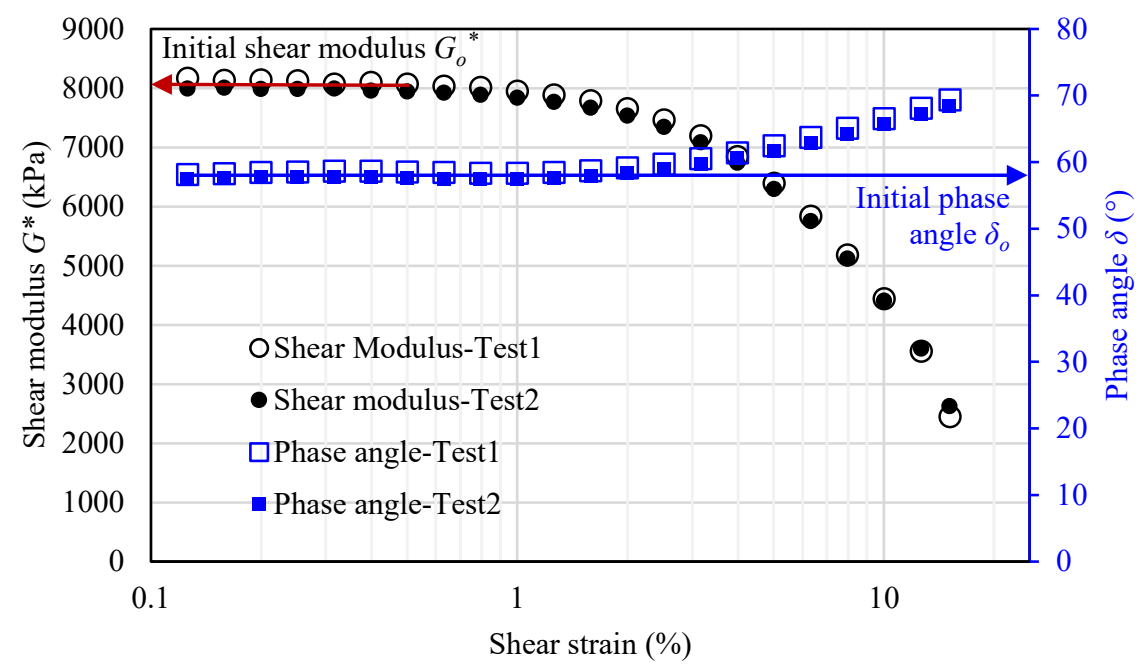

Fig. 2 Linear amplitude sweep (LAS) test results with the shear modulus $G_{o}^{*}$ and phase angle $\delta_{0}$ of the unaged bitumen with $10 \%$ TMP (sample 2) under a strain level of $0.1 \%-15 \%$. The test is conducted at $20{ }^{\circ} \mathrm{C}$ temperature and loading frequency of $10 \mathrm{~Hz}$ for two replicates

The tests are performed at different ageing conditions (unaged, ST-aged by TFOT and LT-aged by PAV). The initial shear modulus (at undamaged conditions) varied significantly due to AACs inclusion, as can be seen in Figure 3. Compared with the control sample (sample 1), samples 2, 3 and 4 caused an increase in stiffness at ST-ageing and LT-ageing conditions. In contrast, samples 5 and 6, which contain Irganox 1076 as a main anti-ageing compound, has shown a considerable decrease in stiffness at all ageing stages. Sample 7, contains 3.5\% DLTDP: furfural (3: 4) maintained the same complex modulus as in the control sample (sample 1) after the ageing conditioning. The combination of furfural, and DLTDP works as primary and secondary anti-oxidants, where furfural works as a freeradical scavenger and DLTDP as a peroxide inhibitor, therefore, prevents oxidation. Since furfural is a liquid with low viscosity and DLTDP is material of low melting point $\left(39-42^{\circ} \mathrm{C}\right)$, this explains the slight reduction in the initial shear modulus and increase in phase angle for sample 7.

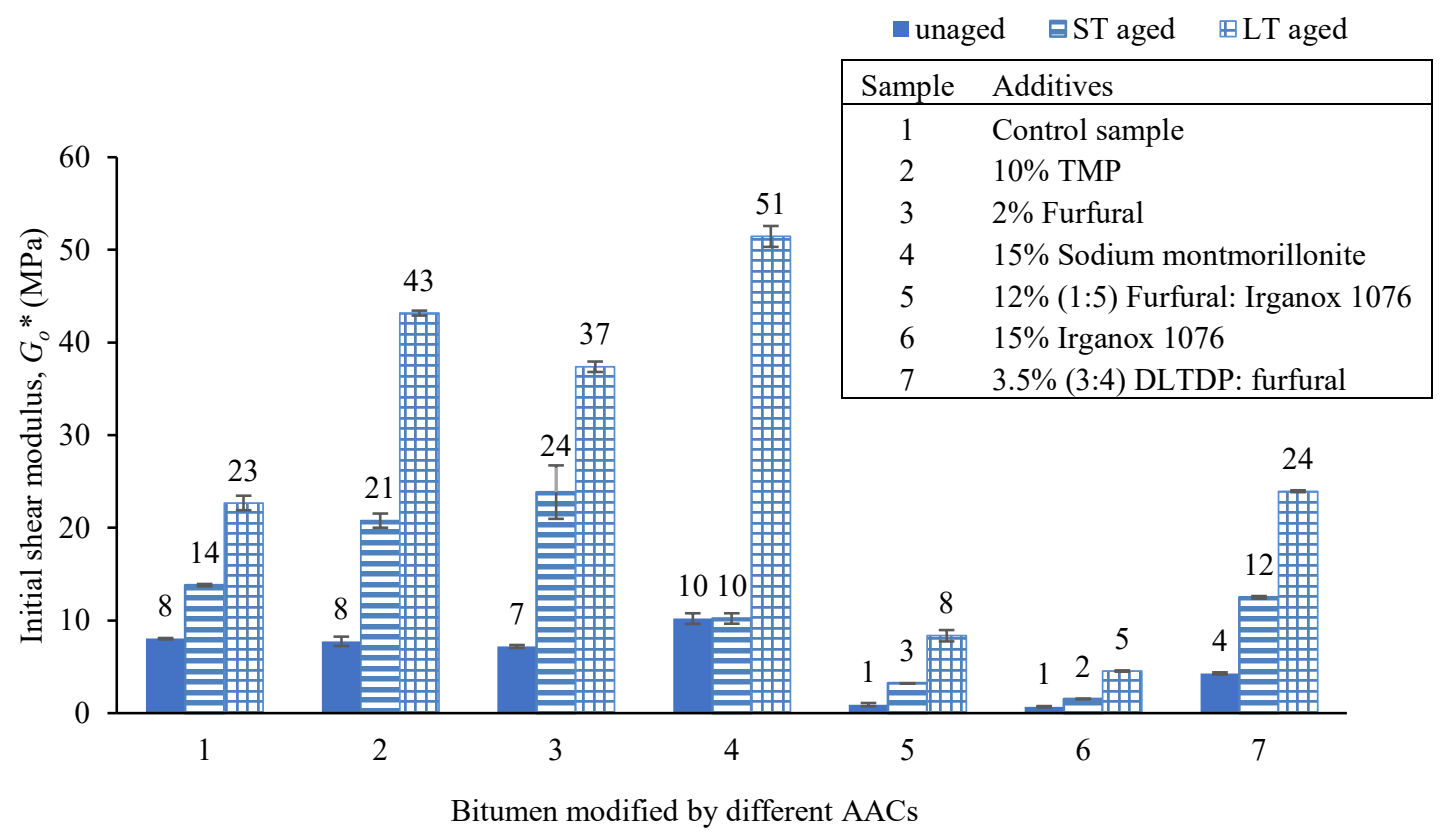


Fig. 3 Initial shear moduli Go* obtained by linear amplitude sweep (LAS) test. The test is conducted on unaged, shortterm (ST, by TFOT) aged and long-term (LT, by PAV) aged bitumen samples modified by different AACs at a temperature of $20^{\circ} \mathrm{C}$ and loading frequency of $10 \mathrm{~Hz}$.

The initial phase angles (shown in Figure 4) demonstrated negligible changes upon the inclusion of AACs, excluding samples 5 and 6 (containing Irganox 1076), which experienced increases in phase angles.

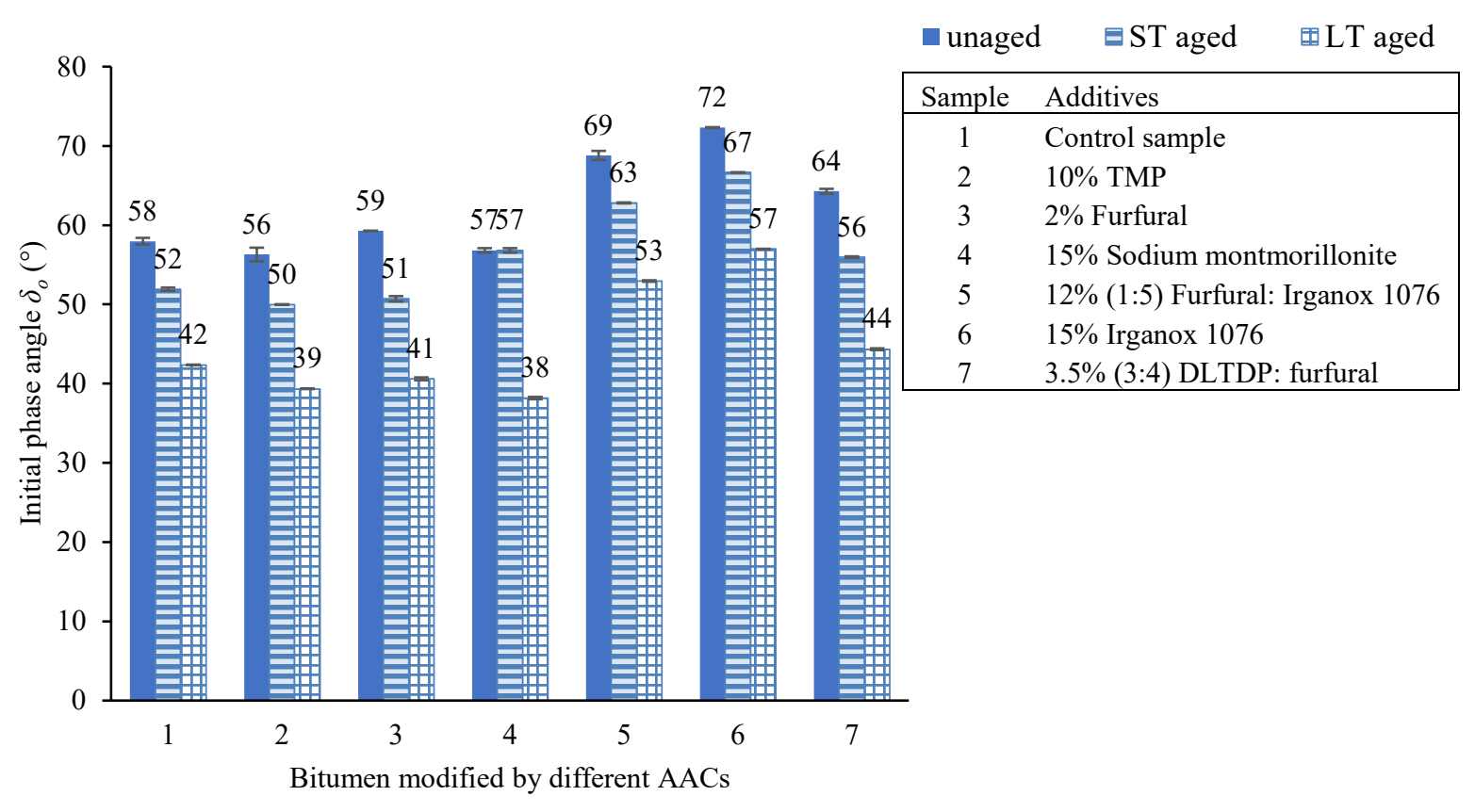

Fig. 4 Initial phase angles $\delta_{o}$ by the linear amplitude sweep (LAS) test. The test is conducted on unaged, short-term (ST, by TFOT) aged and long-term (LT, by PAV) aged bitumen samples modified by different AACs at a temperature of 20 ${ }^{\circ} \mathrm{C}$ and the loading frequency of $10 \mathrm{~Hz}$.

The oxidation ageing occurs when oxygen removes hydrogen atoms from carbon atoms, thereby causing a rise in the proportion of asphaltenes as well as a reduction in the content of resins and most of the aromatic compounds in the bitumen [1]. Irganox 1076 is hindered phenol organic ester anti-oxidant, works as a primary anti-oxidant and prevents thermal oxidation by donating hydrogen atoms for the free radicals that cause oxidation $[1,42]$. Irganox 1076 has a low molecular weight of approximately $531 \mathrm{~g} / \mathrm{mol}$ and low melting temperature $\left(50-55^{\circ} \mathrm{C}\right)$. The low molecular weight is similar to that for the dispersing medium (aromatics) and the non-polar viscous oil (saturates) in the bitumen (300-800 g/mol). Therefore, Irganox 1076 can decrease the viscosity for modified bitumen, leading to a significantly reduced modulus and increased phase angle, as shown in Figures 3 and 4. Based on these results, one may deduce that modified bitumen with Irganox 1076 alone may not be a suitable anti-ageing additive with satisfying engineering performance. However, it can be feasible to use Irganox 1076 in combination with highsurface-area fillers, such as nano-silica (which can improve the rutting resistance and reduce susceptibility to oxidation by interacting with the polar aromatics and asphaltenes [1]).

One of the common problems encountered with AACs is that they can perish with time due to ageing and exposure to environmental conditions. It is noted from Figures 3 and 4 that the long-term aged AAC-modified bitumen samples maintained a different behaviour than that for the long-term aged control sample, suggesting the additives still affect the material behaviour even after exposure to long-term ageing. This behaviour indirectly indicates good stability for these anti-ageing compounds, although chemical tests are needed to confirm this theory.

\subsection{Time Sweep Test Results}

The time sweep (SW) test is conducted for unaged and LT-aged samples at intermediate temperature conditions (20 ${ }^{\circ} \mathrm{C}$ ) to evaluate fatigue performance of AAC-modified bitumen. The phase angles and shear moduli are recorded up to 24,000 loading cycles, as can be seen in Figure 5 . 


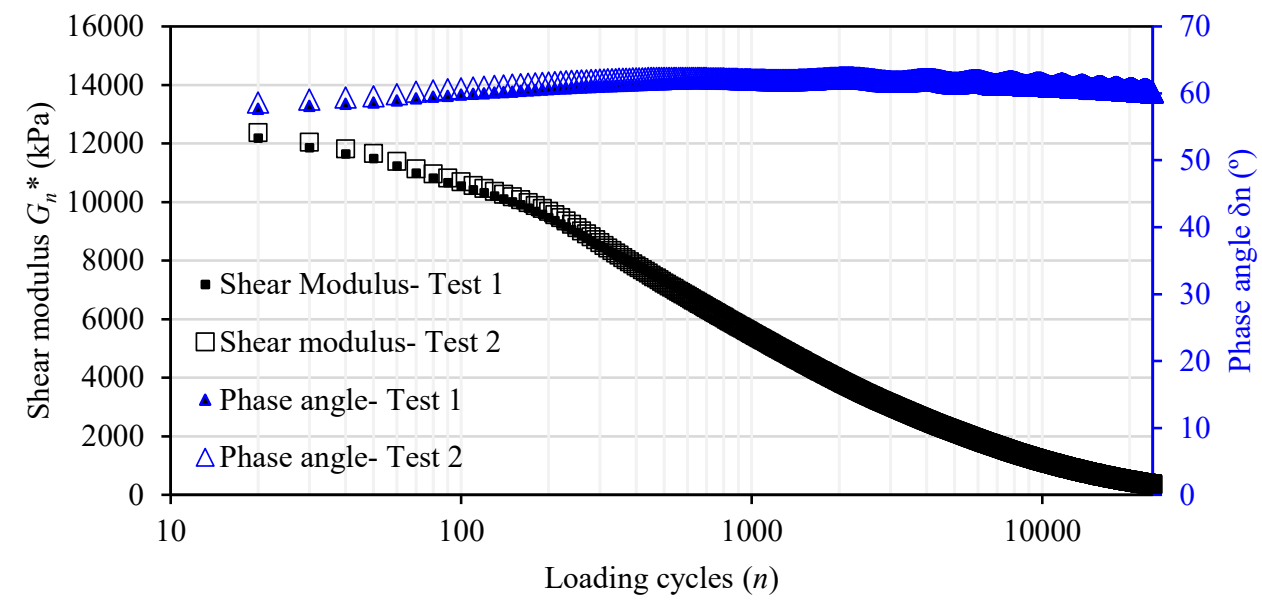

Fig. 5 Time sweep (TS) test results for sample 2 (bitumen with $10 \%$ TMP) for the unaged condition. The test is conducted at $20{ }^{\circ} \mathrm{C}$ temperature, $10 \mathrm{~Hz}$ loading frequency, $5 \%$ strain level, and up to 24,000 cycles.

The parameters phase angle $\delta_{n=24,000}$ and shear modulus $\mid G_{n=24,000}{ }^{*}$ at $(n=24,000)$ loading cycles are obtained by TS tests for LT-aged samples. The crack length at $(n=24,000)$ is calculated using DSR-C model in Eq. (4). Both LAS and TS results are used to obtain predicted crack length values $\left(c_{p}\right)$. For comparison, measured crack length $\left(c_{m}\right)$ at ( $n=24,000$ loading cycles) for all AAC-modified bitumen samples is determined by IAM, as shown in Figure 6 . Figure 6 shows the predicted and measured crack lengths are in good and consistent agreement, and there is a proportional relation between calculated and measured crack lengths at all ages (for unaged, ST-aged and LT-aged samples) with an $R^{2}$ value of 0.7602 . Moreover, the correlation between measured and calculated crack lengths is more reliable and consistent for LT-aged samples with an $R^{2}$ value of 0.9567 . The reliable correlation with less disparity for LT-aged samples is a promising finding, because it is more vital for measuring fatigue resistance performance since asphalt pavements are susceptible to fatigue failure at later ageing stages of their service life, and the method proved effective in measuring this value. It is expected that the variation between predicted and measured crack lengths is caused by (1) Possible errors in measuring the crack length by IAM, (2) The high healing capacity for unaged and ST-aged samples.

Generally, results indicate that the crack length predicted by DSR-C model (Eq. 4) can effectively evaluate and differentiate the fatigue performance of bitumen modified by AACs, particularly for those at long-term ageing conditions.
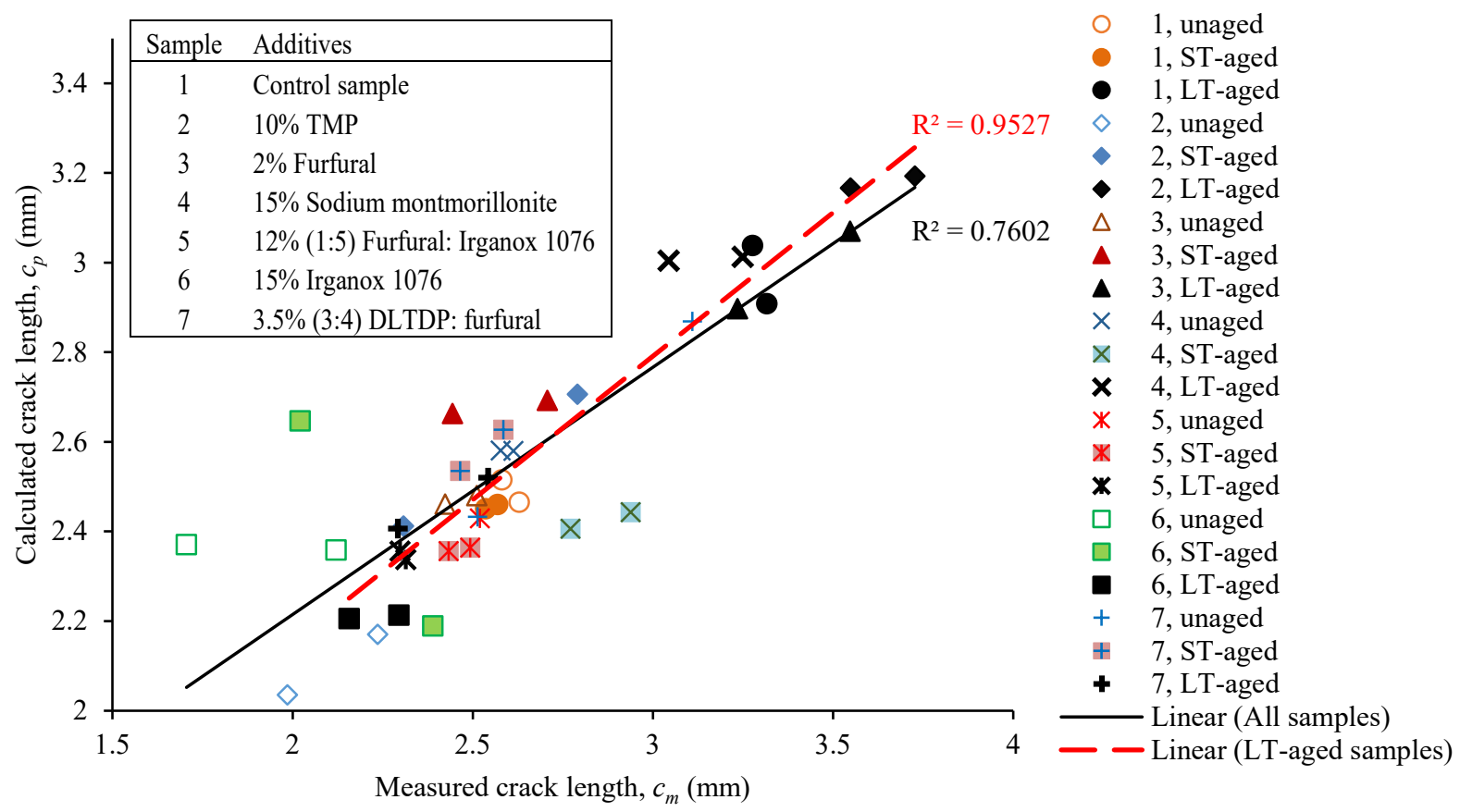
Fig. 6 Predicted crack length $\left(c_{p}\right)$ versus measured crack length $\left(c_{m}\right)$. The predicted crack length is obtained by DSR-C method, and measured crack length obtained by image analysis method (IAM) by using time sweep (TS) and linear amplitude sweep (LAS) tests for samples at different ageing conditions (unaged, ST-ageing, LT-ageing) at $20^{\circ} \mathrm{C}$ temperature and $10 \mathrm{~Hz}$ loading frequency. IAM is conducted at 24,000 loading cycles. Tests are replicated.

It is also observed in Figure 6 that samples 2, 3 and 4 at LT-aging condition show adverse results (larger crack length) in terms of fatigue-cracking resistance when compared with the control sample (sample 1). This behaviour means that even if the AACs in samples 2, 3 and 4 can reduce the oxidation of bitumen, they are unable to reduce fatigue damage. Moreover, samples 5 and 6 experienced the least fatigue damage among other samples. It is reminded that the shear modulus of samples 5 and 6 is significantly reduced due to the addition of AACs, which means they may be unable to provide sufficient stiffness. Sample 7 performed better resistance to fatigue cracking than that for the control bitumen, while still maintained adequate stiffness as indicated by LAS test. Thus, only sample 7 (bitumen modified by (3:4) DLTDP: furfural) has demonstrated a great anti-oxidation and fatigue-resistance performance without significantly reducing stiffness.

For comparison purposes, DER values at $n=24,000$ loading cycle are obtained by (Eq. 3 ). DER values are compared to the measured crack lengths $\left(c_{m}\right)$ in Figure 7. There is a weak correlation between DER and measured crack length for bitumen samples at different ages (unaged, ST-aged and LT-aged) with an $R^{2}$ value of 0.2329, with DER having a bit better correlation to the measured crack lengths for LT-aged samples, with an $R^{2}$ value of 0.4418 .

To examine the fatigue performance against other known parameters, measured crack lengths are plotted against the Superpave fatigue parameter $\left(\left|G_{o} *\right| \cdot \sin \delta_{o}\right)$ developed by the Strategic Highway Research Program (SHRP) [3]. The parameter $\left(\left|G_{o}{ }^{*}\right| \cdot \sin \delta_{o}\right)$ should be minimised for bitumen with good resistance to fatigue cracking. Figure 8 shows that the correlation between measured crack lengths and Superpave fatigue parameter at the initial (undamaged) state is weak, with an $R^{2}$ value of 0.5206 for samples at different ageing conditions (unaged, ST-aged and LTaged), and an $R^{2}$ value of 0.6115 for samples tested at LT-ageing conditions.

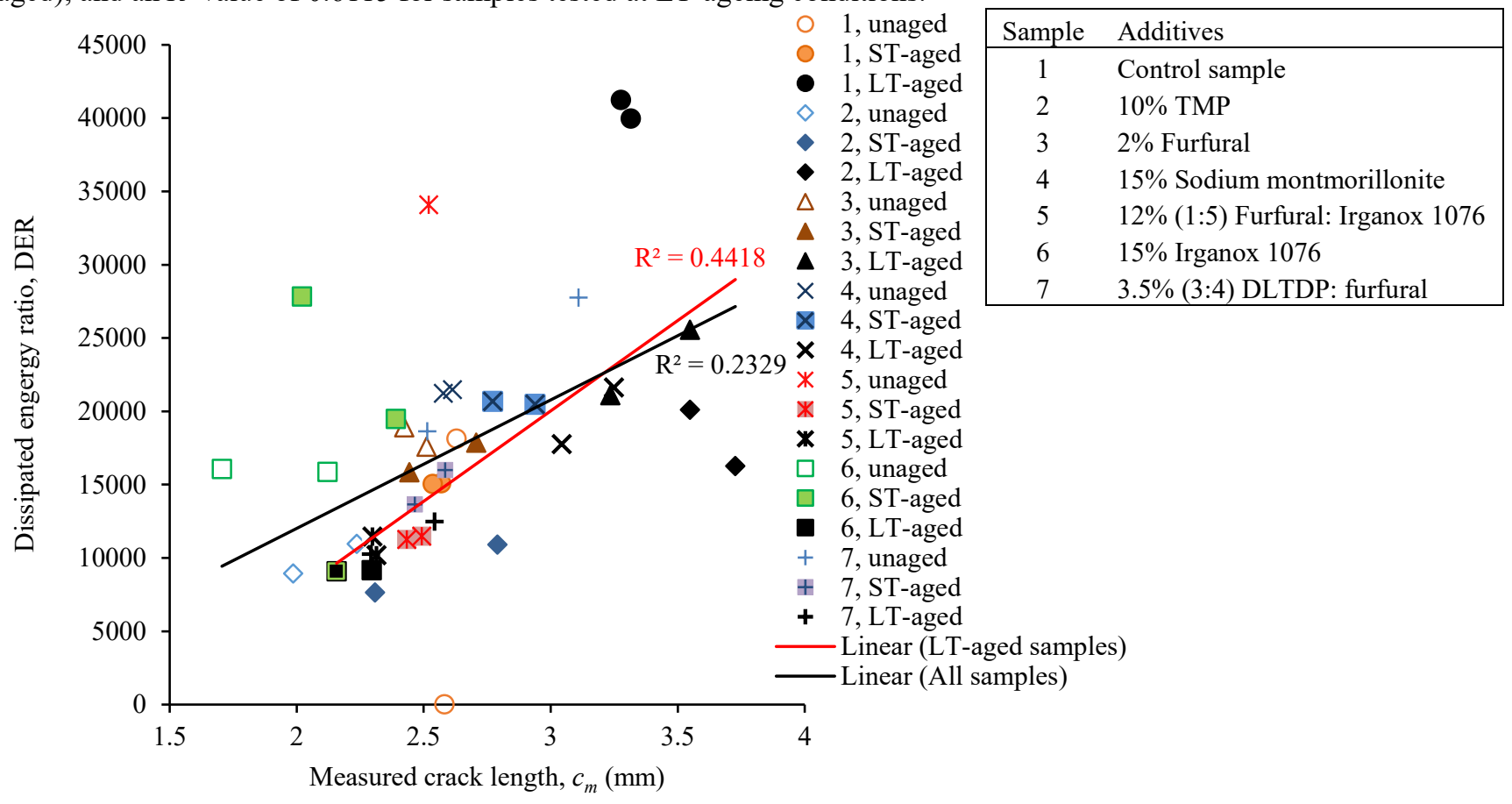


Fig. 7 Dissipated energy ratio (DER) versus measured crack length $\left(c_{m}\right)$. DER and $c_{m}$ are obtained by time sweep (TS) test for samples at different ageing conditions (unaged, ST-ageing, and LT-ageing) at a temperature of $20{ }^{\circ} \mathrm{C}$ and $10 \mathrm{~Hz}$ loading frequency. IAM is conducted at 24,000 loading cycles. Tests are replicated.

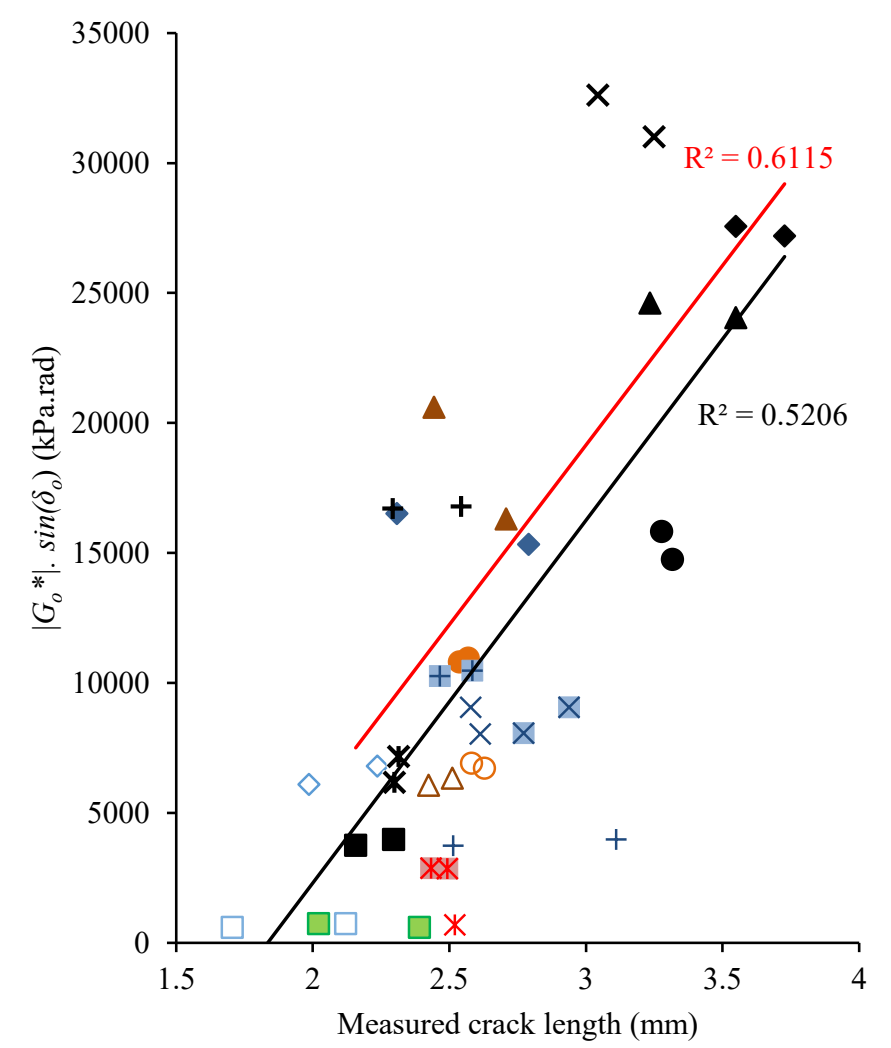

\begin{tabular}{ll|cl|}
\cline { 2 - 3 } & 1, unaged & Sample & Additives \\
\cline { 2 - 3 } & 1, ST-aged & 1 & Control sample \\
- & 1, LT-aged & 2 & $10 \%$ TMP \\
$\diamond$ & 2, unaged & 3 & 2\% Furfural \\
$\bullet$ & 2, ST-aged & 4 & $15 \%$ Sodium montmorillonite \\
$\bullet$ & 2, LT-aged & 5 & $12 \%(1: 5)$ Furfural: Irganox 1076 \\
$\Delta$ & 3, unaged & 6 & $15 \%$ Irganox 1076 \\
$\Delta$ & 3, ST-aged & 7 & $3.5 \%(3: 4)$ DLTDP: furfural \\
\hline & 3, LT-aged & &
\end{tabular}

$\Delta$ 3, LT-aged

$\times 4$, unaged

$\times \quad 4$, ST-aged

$\times \quad 4$, LT-aged

* 5, unaged

* 5 , ST-aged

* 5, LT-aged

$\square$ 6, unaged

$\square \quad 6$, ST-aged

- 6, LT-aged

+7 , unaged

+7, ST-aged

$+\quad 7$, LT-aged

L Linear (All samples)

Linear (LT-aged samples)

Fig. 8 The Superpave fatigue parameter at undamaged state versus measured crack length $\left(c_{m}\right)$. The undamaged fatigue parameter is obtained by linear amplitude sweep (LAS) test for samples at different ageing conditions (unaged, ST-aged, and LT-aged) at intermediate temperature $\left(20{ }^{\circ} \mathrm{C}\right), 5 \%$ strain level and $10 \mathrm{~Hz}$ loading frequency. The measured crack length was obtained by time sweep (TS) test for samples at different ageing conditions (unaged, ST-ageing, and LT-ageing at $20{ }^{\circ} \mathrm{C}$ temperature and $10 \mathrm{~Hz}$ loading frequency. IAM is conducted at 24,000 loading cycles. Tests are replicated.

Comparing Figures 7 and 8 with Figure 6, one can find that the fatigue cracking for AAC-modified bitumen quantified by laboratory-measured crack lengths correlates the best (highest $R^{2}$ values) with the calculated crack length determined by DSR-C model. Thus, it is concluded that DSR-C predicted crack length could evaluate and differentiate the fatigue performance of AAC modified bitumen more reliably than when using DER values or SHRP fatigue parameter. Additionally, all fatigue cracking evaluation methods utilised in this study (DSR-C, DER and SHRP fatigue parameter) demonstrated a better correlation with measured crack length at the LT-ageing conditions than that at the unaged or ST-ageing conditions.

\subsection{Fourier Transform Infrared Spectroscopy}

FTIR test is carried out in duplicates for unaged, ST-aged and LT-aged samples to determine amounts of ageing products in AAC-modified binders. The carbonyl area $(\mathrm{CA})$ forms the band $(\mathrm{C}=\mathrm{O})$ at $1700 \mathrm{~cm}^{-1}$ wavenumber, is utilised to quantify the oxidation ageing in bitumen samples. $\mathrm{CH}_{3}$ peak at wavelength $1377 \mathrm{~cm}^{-1}$ is a reference peak to correct the thickness variation in samples. A detailed description of oxidation quantification methods is reported in the literature [7]. An example of FITR outputs for bitumen is shown in Figure 9. 


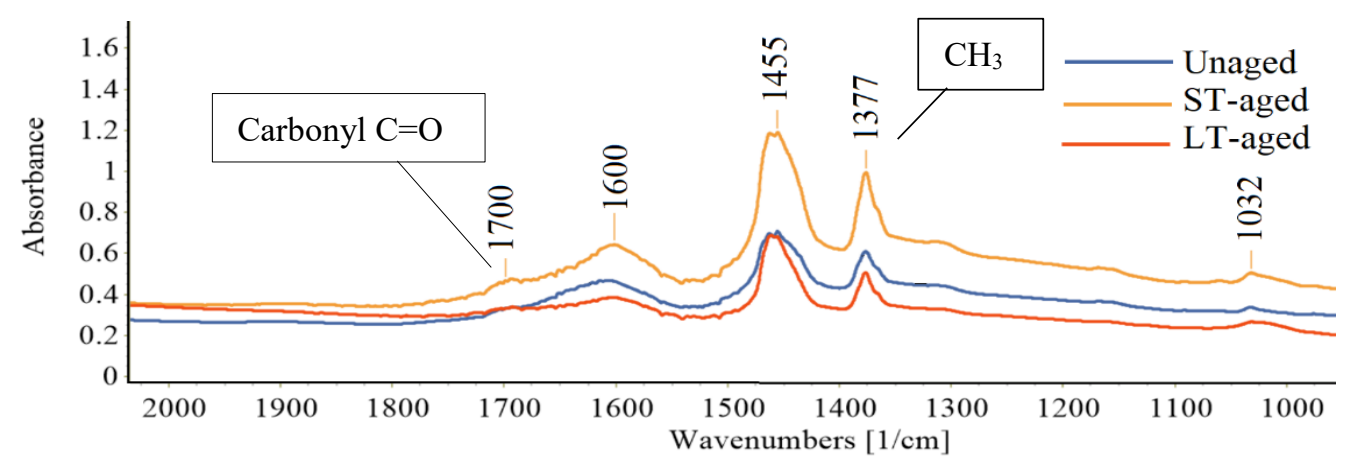

Fig. 9 FTIR spectrum of control bitumen sample (sample 1) at a wave range of (2000-1000) $\mathrm{cm}^{-1}$. The test is conducted for unaged, short-term (ST, by TFOT) aged and long-term (LT, by PAV) aged bitumen samples, showing the oxidation products functional group (carbonyl) at the peak of $1700 \mathrm{~cm}^{-1}$ and functional group $\left(\mathrm{CH}_{3}\right.$ bend) at the peak of $1377 \mathrm{~cm}^{-}$ 1 .

Sulfoxide functional group ( $\mathrm{S}=\mathrm{O}$ band) with $1030 \mathrm{~cm}^{-1}$ wavenumber was neglected in the current study, as it is reported to undergo inconsistent changes due to ageing [17, 43, 44], and because it can reach a stable condition after early stages of laboratory ageing [7].

Results of FTIR test are used to obtain the normalised carbonyl index (NCI). Eqs. (5) and (6) illustrate the carbonyl index $(C I)$ and normalised carbonyl index $(N C I)$, respectively.

$$
\begin{aligned}
& C I=\frac{C A}{R A} \\
& N C I=\frac{C I_{\text {LT aged }}-C I_{\text {unaged }}}{C I_{\text {unaged }}}
\end{aligned}
$$

where

$C I=$ carbonyl index

$C A=$ carbonyl area at peak $1700 \mathrm{~cm}^{-1}$

$R A=$ reference area at peak $1377 \mathrm{~cm}^{-1}$

$C I_{L T \text { aged }}=$ the carbonyl index for LT-aged samples

$C I_{\text {unaged }}=$ the carbonyl index for unaged samples

To reveal the relationship between the oxidation products growth and fatigue performance for AAC-modified bitumen samples, Figure 10 shows NCI (defined by Eq. (6)) against the ratio of change in fatigue crack lengths $\left(\Delta c / c_{\text {unaged }}\right)$ between the LT-aged sample and the corresponding unaged sample, as that defined in Eq. $(7)$.

$$
\Delta c / c_{\text {unaged }}=\frac{c_{\text {LT aged }}-c_{\text {unaged }}}{c_{\text {unaged }}}
$$

where

$c_{L T}$ aged $=$ the predicted crack length for LT-aged samples.

$c_{\text {unaged }}=$ the predicted crack length for unaged samples.

Results show that NCI may be a reliable parameter to reflect the impact of ageing products on the fatigue resistance of AAC-modified binders. Firstly, a good linear proportional correlation $\left(\mathrm{R}^{2}=0.8847\right)$ between the crack length propagation ratio $\left(\Delta c / c_{\text {unaged }}\right)$ and the growth in carbonyl content $(N C I)$ is found for samples $1,2,3$, and 4 (those show less effectiveness in anti-ageing, represented by black marks in Figure 10). The crack length increases linearly with the increase in $N C I$ value. This correlation can be further verified against different bitumen binder types to predict the fatigue resistance behaviour in binders by performing laboratory ageing and FTIR tests. 


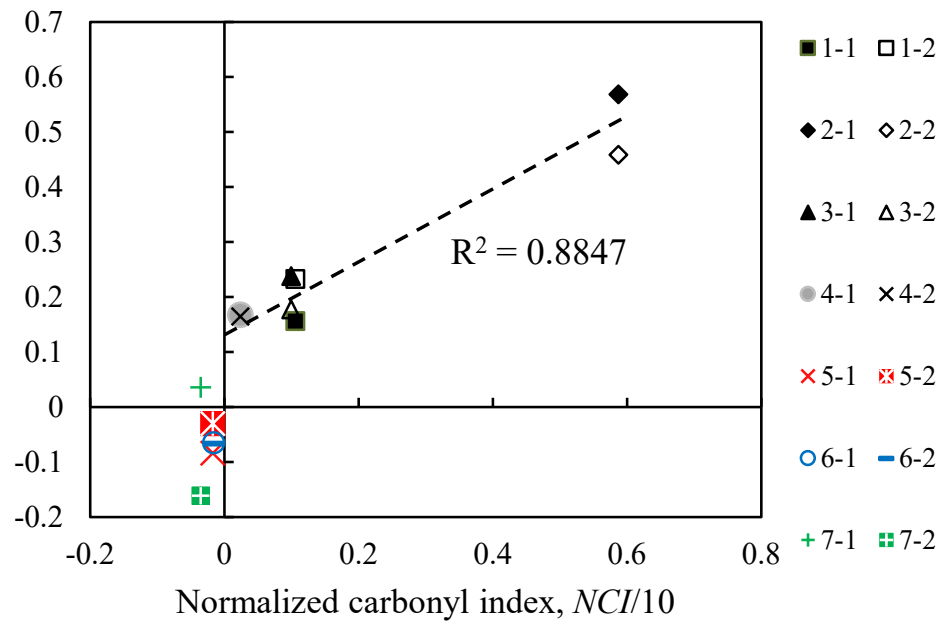

Fig. $10 \mathrm{NCI}$ at LT-aged samples versus the ratio of change in the crack length propagation due to long-term laboratory ageing for all tested samples (note in legends label, the first number represents AAC sample number and the second number represents the number of tests replicates).

Secondly, Figure 10 also shows that samples 5, 6 and 7 (those show high effectiveness in anti-ageing, represented with coloured markers in Figure 10) shown a decrease in both normalised carbonyl index ( $N C I)$ and cracking lengths propagation ratio due to LT-ageing. This observation means the AACs in samples 5, 6 and 7 can reduce both oxidation and fatigue damage by preventing build-up of asphaltene and resin fractions upon exposure to oxygen from ageing conditioning. The $N C I$ retardation (remains unchanged and close to zero) in samples 5,6 and 7 can be attributed to the high carbonyl content in the additives prior to ageing [7]. The decrease in crack length upon ageing proves that by adding these additives, the crack growth for long-term aged binder becomes significantly less than that for unaged samples which ensure the benefits of adding these AACs. Whereas, AACs in samples 3 and 4 did not affect the fatigue resistance and carbonyl development when compared to the control sample (sample 1).

Results suggest that adding furfural alone as a primary anti-oxidant (sample 3) is ineffective in retarding the oxidation. Similarly, the addition of sodium montmorillonite to bitumen (sample 4) is ineffective in reducing carbonyl growth rate. Recent researches reported many beneficial effects of adding nanomaterials to bitumen $[35,36$, 45], including improvements in thermal stability, resistance against rutting, and strengthening bonding with rubber modifiers. However, there is no evidence that nanomaterials can hinder oxygen diffusion into binder film during ageing, thus retard oxidation by preventing oxygen from the air to reach the free-radicals in bitumen binder.

Sample 2 (containing TMP) demonstrated a poor performance, which agrees well with the low oxidation activation energy for TMP-modified bitumen under oven ageing condition from previous work [7]. TMP esters are reaction blocks used in polymer production and lubrication applications [37, 46]. TMP is added to bitumen to retard oxidation by assuming a reaction of $\mathrm{OH}-$ will occur with the acidic compounds of bitumen. An earlier study that involved adding TMP to bitumen and measuring carbonyl content at different ageing intervals suggested a slight to no improvement in NCI with low oxidation activation energy [7]. Due to the unclear behaviour of TMP in the preliminary testing stage, it was included in the current study for further investigation. However, the high crack length values (especially that at LT-ageing condition) and high initial shear modulus obtained for sample 2 suggest that the TMP is ineffective anti-oxidant. TMP alone crystallises at medium/low temperatures; therefore, it led to more susceptibility to fatigue cracking when added to bitumen. Additionally, TMP melts at high temperatures, causing low viscosity for the modified binder. Thus, TMP alone is considered ineffective AAC for bitumen binders.

Samples 5 and 6 possessed high initial phase angles and low shear moduli due to the decrease in viscosity upon the addition of AACs; therefore, they are not recommended, although they achieved good anti-ageing performance (Figure 8), confirming Irganox 1076 is effective in retarding oxidative ageing of bitumen. Sample 7 with 3.5\% (3 DLTDP/4 furfural) demonstrated a better initial shear strength with minimum ageing and fatigue failure compared to other additives. 


\subsection{Oxidation Onset Temperature}

The OOT test results are illustrated in Figure 11 for unaged and LT-aged samples. Results are averaged for two replicates. Sample 2 is not tested because it demonstrates negative impacts on fatigue resistance and carbonyl growth retardation. All results indicate initiation of endothermic reaction at a certain point within the range $\left(20-150{ }^{\circ} \mathrm{C}\right)$; this endothermic reaction means the oxidation initiation process did not commence at this temperature range. As can be seen in Figure 11, the endothermic reaction is initiated at lower temperatures for samples 5, 6 and 7 compared to endothermic initiation temperature of the control sample (sample 1). The endothermic reaction can be a result of the melting of waxy components in bitumen. It is argued that samples 5, 6 and 7 contain fewer asphaltene fractions and higher aromatics content, therefore, this influenced chemical structure organisation and led to lower melting temperatures [40]. Thus, it is decided to examine the high-temperature performance of AAC modified bitumen samples to observe whether the decrease in the viscosity at lower temperatures has an adverse effect on the hightemperature mechanical performance of bitumen. Furthermore, there is no exothermic heat flow at this testing scheme for all examined samples; for this reason, it is concluded that the oxidation onset temperature is exceeding the testing temperature range $\left(20-150^{\circ} \mathrm{C}\right)$.

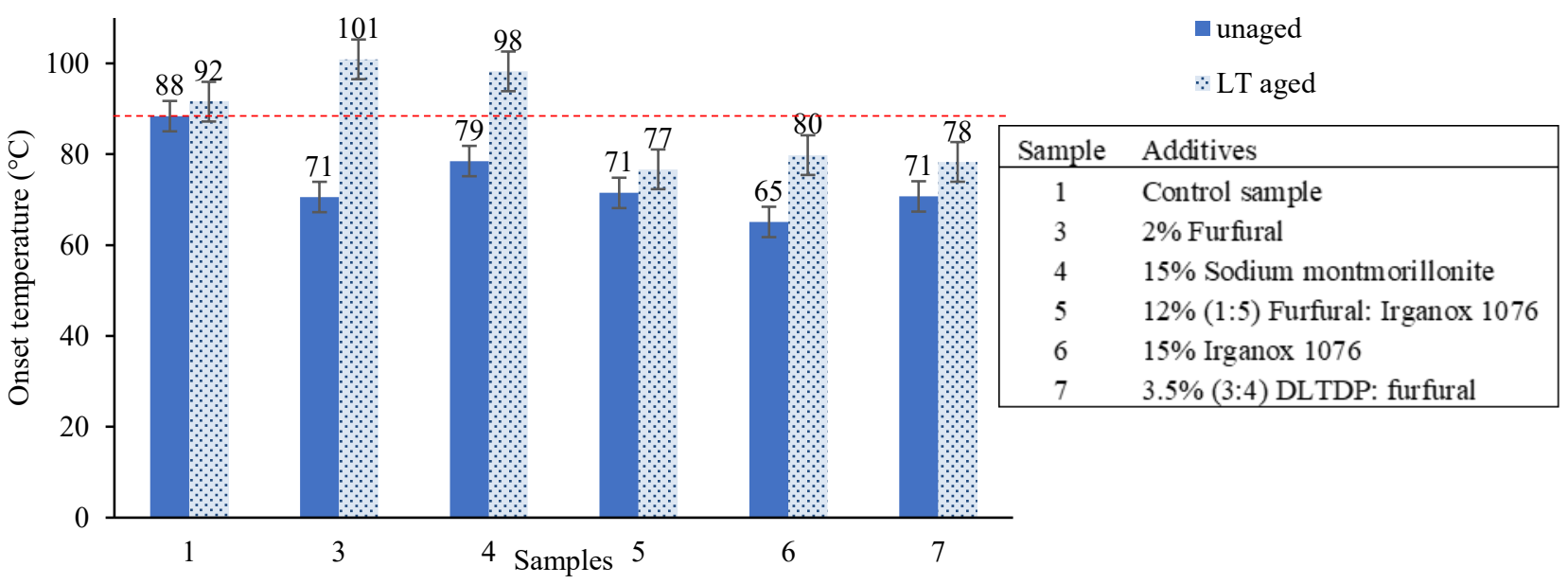

Fig. 11 Endothermic reaction initiation temperature for unaged and long-term (LT, by PAV) aged bitumen samples.

\subsection{DSR at High Temperatures}

The fatigue cracks propagation behaviour at intermediate temperatures and the carbonyl growth both suggested that samples 5, 6 and 7 contain promising AACs. However, samples 5 and 6, which contain Irganox 1076, have suffered a considerable decrease in the initial complex shear modulus (Figure 3). Therefore, samples 5 and 6 considered as improper AACs and not leading to improved engineering performance in this study. Nonetheless, the addition of Irgnox 1076 may still be considered for specific applications with lower PG-grade or when combined with other additives after further testing.

Sample 7 demonstrated good fatigue cracking resistance and anti-oxidative action. However, OOT test indicated a decrease in melting temperature of sample 7 compared to the control sample. For this reason, it is necessary to investigate the rutting susceptibility of the modified sample as well as the performance at high temperatures.

To investigate the high-temperature behaviour (e.g., rutting) of sample 7, first, the high-temperature performance grade (HT-PG) is determined, then it was implemented later for MSCR and LAS tests both at high-temperature conditions. It is found that HT-PG for sample 7 is $64{ }^{\circ} \mathrm{C}$, and HT-PG for the control binder was $70{ }^{\circ} \mathrm{C}$. This finding contradicts with Apeagyei (2011) for DLTDP/furfural additives, as they observed an increase in $\mathrm{HT}$-PG from $64{ }^{\circ} \mathrm{C}$ at control binder to $70^{\circ} \mathrm{C}$ at the modified binder, this variation may be attributed to differences in sample preparation, where Apeagyei (2011) introduced an acid catalyst to mix furfural into the binder [28]. It may also be a result of using a different sample preparation procedure as they mixed the binder at a lower mixing rate of $750 \mathrm{rpm}$ but for four hours, whereas in this study the mixing time was 90 minutes with mixing rate of $4000 \mathrm{rpm}$, which can cause less volatilisation of light compounds.

MSCR test is performed to measure the non-recoverable deformations. The test is usually conducted for rolling thin-film oven aged samples [47], but since the additive caused ageing retardation, the test was also conducted for LT-aged samples as rutting damage may become potential distress when induction of the AACs reduces the ageing. 
Figure 12 shows MSCR results for ST-aged and LT-aged samples (sample 1 and 7). Sample 7 demonstrated increased non-recoverable creep compliance and an unchanged per cent recoverable strain at ST-ageing condition, compared to the control bitumen (sample 1). At ST-ageing condition, a negative recovered strain value is obtained; this occurs when strain increases in unloading phase, in the absence of load, especially when the sample is very soft, and there is almost no recovery. Therefore, the slight increase in strain curve is enough to give a negative value for the total recovery; this slight increase in loading could be a result of rheometer errors at unloading condition [48]. At LT-ageing condition, sample 7 demonstrated a slight increase in the non-recoverable creep compliances and a reduced per cent recoverable strain. This means bitumen samples 7 have less rutting resistance compared to the control bitumen (sample 1) at high temperature. Increased rutting potential can be attributed to the addition of low molecular mass components (furfural and DLTDP), or due to reduction in polarity due to the reaction of these primary and secondary anti-oxidants with bitumen, reducing viscosity and thermal dependency.

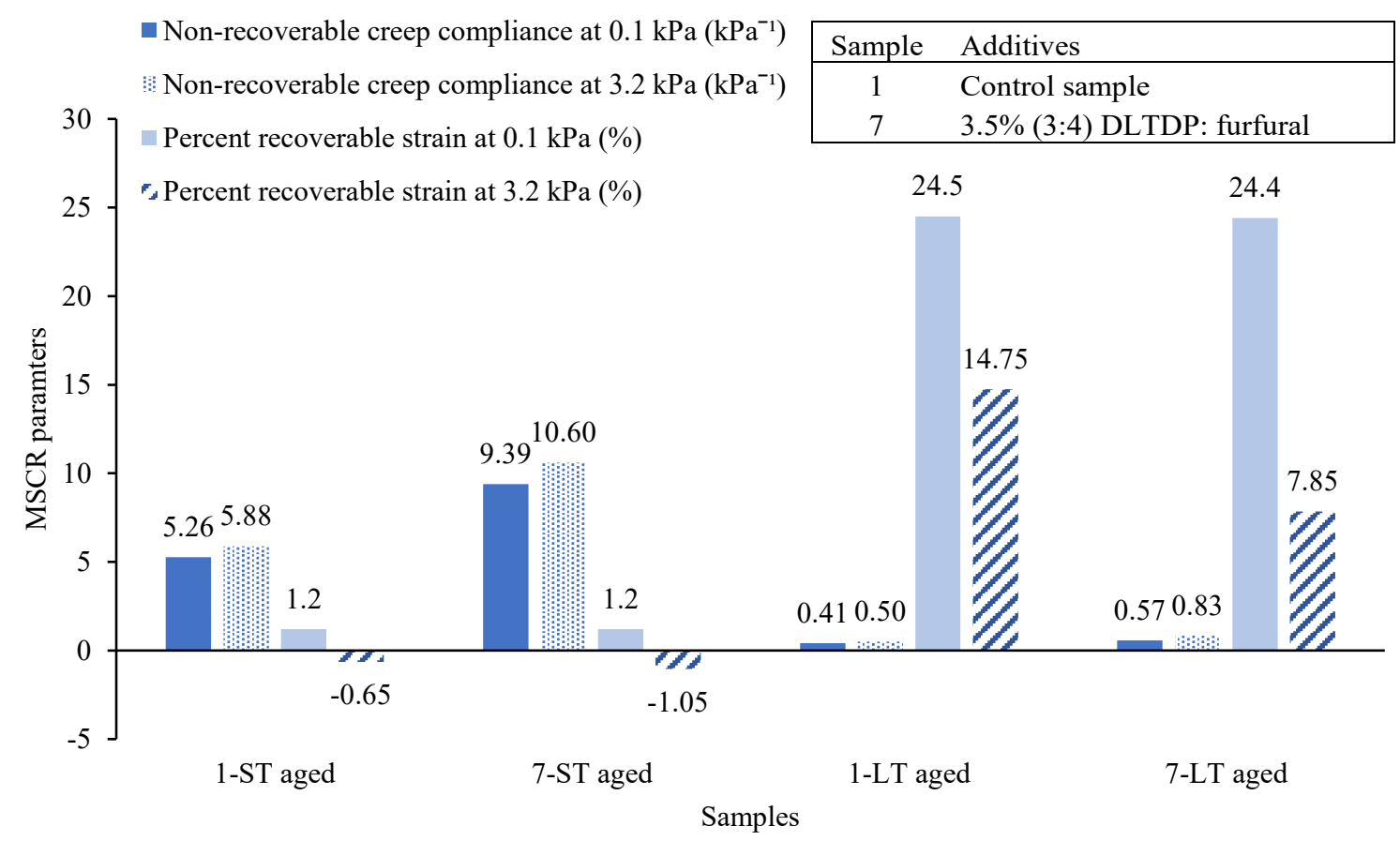

Fig. 12 Multiple stress creep and recovery (MSCR) test parameters at $64^{\circ} \mathrm{C}$ temperature for short-term (ST, by TFOT) aged and long-term (LT, by PAV) aged samples (samples 1 and 7)

\section{Conclusions}

A set of rheological and chemical tests are conducted on bitumen samples modified with six different anti-ageing compounds (AACs). The AACs effectiveness is compared in term of the resistance to fatigue cracking at intermediate temperatures. FTIR tests are conducted to link the chemical structure of bitumen samples with their fatigue performance. The fatigue behaviour is measured by using several approaches (DSR, actual crack length method, predicted crack length, and fatigue parameter). Further tests were carried out at high temperature for the sample with the nominated anti-oxidant to verify their resistance to rutting at high temperatures. The following can be concluded:

1- The compounds (DLTDP/furfural), Irgnaox 1076 and (furfural/Irganox 1076) demonstrated a good antiageing behaviour by retarding carbonyl content growth and decreasing fatigue damage caused by the cyclic loading and long-term ageing conditions. In contrast, the additive Trimethylolpropane TMP caused adverse impacts on the binder in terms of fatigue resistance. Sodium montmorillonite and furfural alone did not show a pronounced effect in terms of fatigue cracking and anti-oxidation activity. The addition of Irgnaox 1076 caused a drop in the initial complex shear modulus. Therefore, it should be used with precaution for certain applications after conducting further tests.

2- The long-term aged AAC-modified bitumen maintained different linear viscoelastic properties than those for the long-term aged control bitumen, which suggests that the additives still have an effect on the material behaviour even after exposure to long-term ageing. This behaviour indirectly indicates good stability for these anti-ageing compounds, although chemical tests are needed to confirm this theory. 
3- Compared to existing fatigue parameters for bitumen such as $\left(\left|G^{*}\right| \cdot \sin \delta\right)$ or dissipated energy ratio (DER), the predicted crack length based on DSR-C model demonstrated a more reliable and consistent agreement with the measured crack lengths, which suggests it is a promising fatigue cracking evaluation criterion for AAC-modified binders.

4- The normalised carbonyl index may be a reliable parameter to reflect the impact of ageing products on the fatigue resistance of AAC-modified binders. For those binders with ineffective AACs (samples 2 to 4 ), the $N C I$ value correlated well (linearly increased) with the increased fatigue crack length after ageing, regardless of the initial carbonyl content in the unaged samples. For those binders with effective AACs (samples 5, 6 and 7), NCI values become negative after ageing, as the fatigue crack length is reduced when those AACs were used in binders. Therefore, with further study, the normalised carbonyl index can be used to evaluate and differentiate the fatigue performance of the AAC-modified binders.

5- Rutting performance of modified bitumen was reduced by the addition of AACs in bitumen at different scales for the various AACs. Therefore, precaution is required when using these additives, considering the properties of origin binder to be modified, and the field conditions where it is applied.

\section{Acknowledgement}

The authors would like to gratefully acknowledge the British Council and China Scholarship Council for the UKChina Joint Research and Innovation Partnership Fund provided to this work. Additionally, the authors would like to gratefully acknowledge the financial support from the Schlumberger Foundation: Faculty for the Future Fellowship program, and that from the European Commission's Horizon 2020 programme via a Marie S. Curie Individual Fellowship (Grant No. 749232).

\section{References}

1. Tauste, R., Moreno-Navarro, F., Sol-Sánchez, M. and Rubio-Gámez, M.C., 2018. Understanding the bitumen ageing phenomenon: A review. Construction and Building Materials, 192, pp.593-609.

2. Hunter, R.N., Self, A., Read, J. and Hobson, E., 2015. The shell bitumen handbook (pp. 744-747). London, UK: ICE Publishing.

3. Anderson, D.A. and Kennedy, T.W., 1993. Development of SHRP binder specification (with discussion). Journal of the Association of Asphalt Paving Technologists, 62.

4. Wang, C., Zhang, H., Castorena, C., Zhang, J. and Kim, Y.R., 2016. Identifying fatigue failure in asphalt binder time sweep tests. Construction and Building Materials, 121, pp.535-546.

5. Petersen, J.C., 2009. A review of the fundamentals of asphalt oxidation: chemical, physicochemical, physical property, and durability relationships. Transportation Research Circular, (E-C140).

6. Gawel, I., Czechowski, F. and Kosno, J., 2016. An environmental friendly anti-ageing additive to bitumen. Construction and Building Materials, 110, pp.42-47.

7. Omairey, E.L., Zhang, Y., Al-Malaika, S., Sheena, H. and Gu, F., 2019. Impact of anti-ageing compounds on oxidation ageing kinetics of bitumen by infrared spectroscopy analysis. Construction and Building Materials, 223, pp.755-764.

8. Xu, G. and Wang, H., 2017. Molecular dynamics study of oxidative aging effect on asphalt binder properties. Fuel, 188, pp.1-10.

9. Bahia, H.U., Zhai, H., Bonnetti, K. and Kose, S., 1999. Nonlinear viscoelastic and fatigue properties of asphalt binders. Journal of the Association of Asphalt Paving Technologists, 68, pp.1-34.

10. Pronk, A.C. and Hopman, P.C., 1991. Energy dissipation: the leading factor of fatigue (No. Paper 17).

11. Ghuzlan, K.A. and Carpenter, S.H., 2000. Energy-derived, damage-based failure criterion for fatigue testing. Transportation research record, 1723(1), pp.141-149.

12. Anderson, D., Hir, Y., Marasteanu, M., Planche, J.P., Martin, D. and Gauthier, G., 2001. Evaluation of fatigue criteria for asphalt binders. Transportation Research Record: Journal of the Transportation Research Board, (1766), pp.48-56.

13. Wang, C., Xie, W. and Underwood, B.S., 2018. Fatigue and healing performance assessment of asphalt binder from rheological and chemical characteristics. Materials and Structures, 51(6), p.171.

14. Zhang, Y. and Gao, Y., 2019. Predicting crack growth in viscoelastic bitumen under a rotational shear fatigue load. Road Materials and Pavement Design, pp.1-20.

15. Hintz, C. and Bahia, H., 2013. Understanding mechanisms leading to asphalt binder fatigue in the dynamic shear rheometer. Road Materials and Pavement Design, 14(sup2), pp.231-251.

16. Shan, L., Tian, S., He, H. and Ren, N., 2017. Internal crack growth of asphalt binders during shear fatigue process. Fuel, 189, pp.293-300. 
17. Xu, G., Wang, H. and Zhu, H., 2017. Rheological properties and anti-ageing performance of asphalt binder modified with wood lignin. Construction and Building Materials, 151, pp.801-808.

18. Wu, S.P., Pang, L., Mo, L.T., Chen, Y.C. and Zhu, G.J., 2009. Influence of ageing on the evolution of structure, morphology and rheology of base and SBS modified bitumen. Construction and Building Materials, 23(2), pp.1005-1010.

19. Ameri, M., Mansourkhaki, A. and Daryaee, D., 2018. Evaluation of fatigue behavior of high reclaimed asphalt binder mixes modified with rejuvenator and softer bitumen. Construction and Building Materials, 191, pp.702-712.

20. Wang, C. and Wang, Y., 2019. Physico-chemo-rheological characterisation of neat and polymer-modified asphalt binders. Construction and Building Materials, 199, pp.471-482.

21. Yang, Y., Zhang, Y., Omairey, E., Cai, J., Gu, F. and Bridgwater, A.V., 2018. Intermediate pyrolysis of organic fraction of municipal solid waste and rheological study of the pyrolysis oil for potential use as biobitumen. Journal of cleaner production, 187, pp.390-399.

22. Sun, D., Yu, F., Li, L., Lin, T. and Zhu, X.Y., 2017. Effect of chemical composition and structure of asphalt binders on self-healing. Construction and Building Materials, 133, pp.495-501.

23. Jennings, P.W., Pribanic, J.A.S., Dawson, K.R. and Bricca, C.E., 1981. HPLC and NMR spectroscopy to characterise asphaltic materials. Am. Chem. Soc., Div. Pet. Chem., Prepr.;(United States), 26(CONF810813-(Vol. 2)).

24. McGennis, R.B., Shuler, S. and Bahia, H.U., 1994. Background of superpave asphalt binder test methods. Final report (No. FHWA-SA-94-069).

25. Hajj, R. and Bhasin, A., 2018. The search for a measure of fatigue cracking in asphalt binders-a review of different approaches. International Journal of Pavement Engineering, 19(3), pp.205-219.

26. Gao, Y., Zhang, Y., Yang, Y., Zhang, J. and Gu, F., 2019. Molecular dynamics investigation of interfacial adhesion between oxidised bitumen and mineral surfaces. Applied Surface Science, 479, pp.449-462.

27. Gao, Y., Zhang, Y., Gu, F., Xu, T. and Wang, H., 2018. Impact of minerals and water on bitumen-mineral adhesion and debonding behaviours using molecular dynamics simulations. Construction and Building Materials, 171, pp.214-222.

28. Apeagyei, A.K., 2011. Laboratory evaluation of anti-oxidants for asphalt binders. Construction and Building Materials, 25(1), pp.47-53.

29. Liu, H.Y., Zhang, H.L., Hao, P.W. and Zhu, C.Z., 2015. The effect of surface modifiers on ultraviolet ageing properties of nano-zinc oxide modified bitumen. Petroleum Science and Technology, 33(1), pp.72-78.

30. Yao, H., You, Z., Li, L., Lee, C.H., Wingard, D., Yap, Y.K., Shi, X. and Goh, S.W., 2012. Rheological properties and chemical bonding of asphalt modified with nanosilica. Journal of Materials in Civil Engineering, 25(11), pp.1619-1630.

31. Yu, J., Zeng, X., Wu, S., Wang, L. and Liu, G., 2007. Preparation and properties of montmorillonite modified asphalts. Materials Science and Engineering: A, 447(1-2), pp.233-238.

32. You, Z., Mills-Beale, J., Foley, J.M., Roy, S., Odegard, G.M., Dai, Q. and Goh, S.W., 2011. Nanoclaymodified asphalt materials: Preparation and characterisation. Construction and Building Materials, 25(2), pp.1072-1078.

33. ASTM D1754-97(2002), Standard Test Method for Effect of Heat and Air on Asphaltic Materials (ThinFilm Oven Test), ASTM International, West Conshohocken, PA, 1997, www.astm.org

34. ASTM D6521-18, Standard Practice for Accelerated Ageing of Asphalt Binder Using a Pressurised Ageing Vessel (PAV), ASTM International, West Conshohocken, PA, 2018, www.astm.org

35. Ghile, D.B., 2006. Effects of nanoclay modification on rheology of bitumen and on performance of asphalt mixtures.

36. Ortega, F.J., Navarro, F.J., García-Morales, M. and McNally, T., 2017. Effect of shear processing on the linear viscoelastic behaviour and microstructure of bitumen/montmorillonite/MDI ternary composites. Journal of industrial and engineering chemistry, 48, pp.212-223.

37. Yunus, R., Fakhru'l - Razi, A., Ooi, T.L., Iyuke, S.E. and Perez, J.M., 2004. Lubrication properties of trimethylolpropane esters based on palm oil and palm kernel oils. European journal of lipid science and technology, 106(1), pp.52-60.

38. ASTM D7405-15, Standard Test Method for Multiple Stress Creep and Recovery (MSCR) of Asphalt Binder Using a Dynamic Shear Rheometer, ASTM International, West Conshohocken, PA, 2015, Www.astm.org

39. AASHTO T315-12-UL, 2012. Standard method of test for determining the rheological properties of asphalt binder using a dynamic shear rheometer (DSR).

40. Harrison, I.R., Wang, G. and Hsu, T.C., 1992. A differential scanning calorimetry study of asphalt binders (No. SHRP-A/UFR-92-612). 
41. Focke, W. and Van Der Westhuizen, I., 2009. Oxidation induction time and oxidation onset temperature of polyethylene in air: testing Gimzewski's postulate. Journal of thermal analysis and calorimetry, 99(1), pp.285-293.

42. Dessouky, S., Contreras, D., Sanchez, J. and Park, D., 2015. Anti-Oxidants' Effect on Bitumen Rheology and Mixes' Mechanical Performance. In Innovative materials and design for sustainable transportation infrastructure (pp. 8-18).

43. Ouyang, C., Wang, S., Zhang, Y. and Zhang, Y., 2006. Improving the ageing resistance of styrene-butadiene-styrene tri-block copolymer modified asphalt by addition of anti-oxidants. Polymer degradation and stability, 91(4), pp.795-804.

44. Herrington, P.R., 1995. Thermal decomposition of asphalt sulfoxides. Fuel, 74(8), pp.1232-1235.

45. Yao, H., You, Z., Li, L., Goh, S.W., Lee, C.H., Yap, Y.K. and Shi, X., 2013. Rheological properties and chemical analysis of nanoclay and carbon microfiber modified asphalt with Fourier transform infrared spectroscopy. Construction and Building Materials, 38, pp.327-337.

46. Cuellar Jr, J.P., 1977. Degradation studies of a trimethylolpropane triheptanoate lubricant basestock (No. SWRI-RS-657). SOUTHWEST RESEARCH INST SAN ANTONIO TX.

47. Subhy, A., 2017. Advanced analytical techniques in fatigue and rutting related characterisations of modified bitumen: Literature review. Construction and Building Materials, 156, pp.28-45.

48. Soenen, H., Blomberg, T., Pellinen, T. and Laukkanen, O.V., 2013. The multiple stress creep-recovery test: a detailed analysis of repeatability and reproducibility. Road Materials and Pavement Design, 14(sup1), pp.2-11. 